\title{
EXAMEN DE LOS INSTRUMENTOS DE TUTELA PREVISTOS EN LA DIRECTIVA, DEL PARLAMENTO Y DEL CONSEJO, RELATIVA A LAS ACCIONES DE REPRESENTACIÓN PARA LA TUTELA DE LOS INTERESES COLECTIVOS DE LOS CONSUMIDORES
}

\author{
Faustino Cordón Moreno \\ Catedrático de Derecho Procesal \\ Universidad de Navarra
}

Title: Examination of the guardianship instruments provided for in the directive, of the Parliament and Council, concerning representative actions for the protection of the collective interests of consumers

Resumen: Se expone el contenido de la Directiva, resaltando los diferentes tipos de tutela (acciones) de los intereses colectivos de los consumidores que se prevén, la legitimación de las entidades habilitadas y las medidas de tipo procesal, y comparando su regulación con las normas de Derecho interno en el que estos intereses son también objeto de protección.

Abstract: The content of the Directive is presented in this paper, highlighting the different types of protection (actions) of the collective interests of consumers that are foreseen, the legitimacy of the qualified entities and the procedural measures, and comparing its regulation with the rules of national law in which these interests are also protected.

Palabras clave: consumidores, acciones colectivas, entidades habilitadas, normas procesales.

Key words: consumers, collective actions, qualified entities, procedural rules.

\section{Introducción}

La Directiva apareció en el Diario Oficial de la Unión Europea de 4 de diciembre de 2020, entrará en vigor a los veinte días de su publicación (el 24 de diciembre de 2020) y deberá ser transpuesta, a lo más tardar, el 25 de diciembre de 2022, siendo aplicables las disposiciones correspondientes a partir del 25 de junio de 2023 (art. 24). 
Revista CESCO, N. $36 / 2020$

doi.org/10.18239/RCDC_2020.36.2639
Faustino Cordón Moreno

Examen de los instrumentos de tutela previstos en la Directiva, del Parlamento y del Consejo, relativa a las acciones de representación para la tutela de los intereses colectivos de los consumidores

Partiendo de que la anterior (Directiva 2009/22/CE del Parlamento Europeo y del Consejo, que queda derogada) "no abordaba suficientemente las dificultades relativas a hacer cumplir la normativa en materia de consumo" (considerado 1 ), se propone como objetivo "reforzar los mecanismos procesales de protección de los intereses colectivos de los consumidores, para incluir tanto medidas de cesación como medidas resarcitorias" (considerando 1), aunque no se olvida de proporcionar "salvaguardias adecuadas para evitar un ejercicio abusivo de la acción procesal" (art. 1), que obstaculizaría injustificadamente la capacidad de las empresas para ejercer su actividad en el mercado interior ${ }^{1}$.

A tal fin se regulan las llamadas "acciones de representación", para cuyo ejercicio, ante los tribunales (o también autoridades administrativas), se reconoce legitimación a "entidades habilitadas que representen los intereses colectivos de los consumidores" para "el ejercicio de acciones de representación para obtener tanto medidas de cesación como medidas resarcitorias frente a los empresarios que infrinjan disposiciones del Derecho de la Unión" (considerando 8).

La nueva regulación no impide que los Estados miembros adopten o mantengan en vigor medios procesales de protección de los intereses colectivos de los consumidores en el ámbito nacional (art. 1.2), dejando a su criterio "integrar el mecanismo procesal para las acciones de representación que se exige en la presente Directiva." ${ }^{2}$ Tampoco -contiene disposiciones sobre cada aspecto del procedimiento, correspondiendo a los Estados miembros establecer normas, por ejemplo, sobre admisibilidad, prueba o vías de recurso, aplicables a dichas acciones; aunque tales normas "no deben obstaculizar el funcionamiento efectivo del mecanismo procesal para las acciones de representación que exige la presente Directiva"; por ejemplo, "(d)e conformidad con el principio de no discriminación, los presupuestos de admisibilidad aplicables a determinadas acciones de representación transfronterizas no deben ser diferentes de los que se aplican a determinadas acciones de representación nacionales."

La aplicación de este principio de autonomía procesal de los diferentes Estados miembros determina que, en nuestro ordenamiento, en el que, como diré, están ya previstas las acciones colectivas para la protección de los derechos e intereses de los consumidores que contempla la Directiva, puedan seguir vigentes en lo esencial las

\footnotetext{
${ }^{1}$ Para prevenir un uso indebido de las acciones de representación -dice en el Considerando 10-, "debe evitarse la concesión de indemnizaciones punitivas y deben establecerse normas sobre determinados aspectos procesales, como la designación y la financiación de las entidades habilitadas."

${ }^{2}$ La integración puede producirse "como un elemento de un mecanismo procesal existente para la obtención de medidas colectivas de cesación o resarcitorias, o como un elemento de un nuevo mecanismo procesal para la obtención de esas medidas, o como un mecanismo procesal distinto, siempre que al menos un mecanismo procesal nacional para las acciones de representación cumpla lo dispuesto en la presente Directiva... Cuando existan mecanismos procesales a escala nacional además del mecanismo procesal que exige la presente Directiva, la entidad habilitada debe poder elegir qué mecanismo procesal utilizar" (considerando 11).
} 
Revista CESCO, N. ${ }^{\circ} 36 / 2020$

doi.org/10.18239/RCDC_2020.36.2639
Faustino Cordón Moreno

Examen de los instrumentos de tutela previstos en la Directiva, del

Parlamento y del Consejo, relativa a las acciones de representación para la tutela de los intereses colectivos de los consumidores

normas reguladoras de este tipo de tutela, que no se oponen a ella; siquiera su transposición al Derecho interno exija incorporar algunas de las medidas en ella reguladas.

\section{2. Ámbito de aplicación}

El ámbito de aplicación de la Directiva aparece delimitado en un triple aspecto:

(i) La Directiva es consciente de que "Ios consumidores actúan ahora en un mercado cada vez más globalizado y digitalizado" y, por eso, su alcance se extiende, "además de a la normativa general de protección de los consumidores, a ámbitos como la protección de datos, los servicios financieros, los viajes y el turismo, la energía y las telecomunicaciones" (considerando 13). El resultado es la ampliación del ámbito material de protección en su artículo 2.1: "La presente Directiva se aplica a las acciones de representación ejercitadas frente a actos de empresarios que infrinjan las (numerosas, hasta 66) disposiciones del Derecho de la Unión recogidas en el anexo I, incluidas las disposiciones de transposición al Derecho interno de aquellas, que perjudiquen o puedan perjudicar los intereses colectivos de los consumidores." $Y$ se aplica en la medida en que esas disposiciones protejan los intereses de los consumidores, "independientemente de si se hace referencia a ellos como consumidores o como viajeros, usuarios, clientes, inversores minoristas, clientes minoristas, titulares de datos o de otro modo." Aunque, obviamente, con el límite de que las personas físicas que se hayan visto o puedan verse perjudicadas por dichas infracciones tengan la consideración de consumidores (Considerando 14).

(ii) Ese mismo precepto (art. 2.1) extiende la aplicación de las acciones de representación tanto a las infracciones nacionales como a las transfronterizas, que también estás previstas en nuestro ordenamiento (art. 55 LGDCU), "incluidas aquellas que hayan cesado antes de que se haya ejercitado o haya concluido la acción de representación", ya que "puede ser necesario prevenir la repetición de la práctica mediante su prohibición, declarar que una determinada práctica constituye una infracción o facilitar soluciones para los consumidores" (Considerando 20).

(iii) $Y$, por último, prevé que tales acciones puedan ejercitarse tanto en procedimientos judiciales como en administrativos. La decisión se deja al criterio de los Estados miembros, aunque la opción por extender la protección a los segundos (procedimientos administrativos) "debe entenderse sin perjuicio del derecho a una tutela judicial efectiva conforme al artículo 47 de la Carta, en virtud del cual los Estados miembros deben velar por que consumidores y empresarios tengan derecho a una tutela judicial efectiva frente a cualquier decisión administrativa adoptada de conformidad con las disposiciones nacionales de transposición de la presente Directiva", incluyendo la posibilidad de obtener una resolución de suspensión de la ejecución de la decisión impugnada, de conformidad con el Derecho nacional (Considerando 19). 


\section{Legitimación para el ejercicio de las acciones de representación}

\subsection{Las previsiones de la Directiva}

La legitimación para el ejercicio de las acciones de representación se reconoce a las entidades habilitadas designadas por los Estados miembros para tal fin. Su régimen se contiene en el artículo 4 de la Directiva y se puede resumir en los siguientes puntos:

(i) Las entidades habilitadas pueden representar a consumidores de diversos Estados miembros y ser designadas para ejercitar acciones de representación nacionales o transfronterizas (o ambas). ${ }^{3}$ En el segundo caso, las entidades habilitadas deben cumplir los requisitos legalmente exigidos por la Directiva ${ }^{4}$; en el primero, corresponde a los Estados miembros establecer libremente con arreglo al Derecho nacional los criterios de designación que se apliquen a dichas entidades. pudiendo imponer también el cumplimiento de los requisitos anteriores (considerando 26). Al respecto, dice el considerando 24, "(I)as organizaciones de consumidores, en

3 El Considerando 23 de la Directiva explica la distinción entre estos dos tipos de acciones de representación: "Cuando una entidad habilitada ejercite una acción de representación en un Estado miembro distinto de aquel en el que haya sido designada, dicha acción debe considerarse una acción de representación transfronteriza. Cuando una entidad habilitada ejercite una acción de representación en el Estado miembro en el que haya sido designada, dicha acción debe considerarse una acción de representación nacional, aun cuando se ejercite frente a un empresario domiciliado en otro Estado miembro o mediante dicha acción se represente a consumidores de varios Estados miembros. A fin de determinar el tipo de acción de representación que se ejercita, debe utilizarse como criterio determinante en qué Estado miembro se ejercita la acción de representación. Por esta razón, una acción de representación nacional no debe poder transformarse en una acción de representación transfronteriza en el curso de un procedimiento, ni viceversa."

${ }^{4}$ Los requisitos exigidos en el art. 4.3 son los siguientes: a) ser una persona jurídica constituida de conformidad con el Derecho nacional del Estado miembro de su designación y que pueda demostrar que ha desempeñado de manera efectiva y pública una actividad durante doce meses en el ámbito de la protección de los intereses de los consumidores antes de su solicitud de designación; b) su finalidad estatutaria debe demostrar que tiene un interés legítimo en proteger los intereses de los consumidores tal como establecen las disposiciones del Derecho de la Unión que se recogen en el anexo I; c) ser una entidad sin ánimo de lucro; d) no estar incursa en un procedimiento de insolvencia ni estar declarada insolvente; e) ser independiente y no está influida por personas distintas de los consumidores, en particular, por empresarios, que tengan un interés económico en el ejercicio de cualquier acción de representación, también en el supuesto de financiación por terceros, y a tal fin ha establecido procedimientos para evitar tal influencia, así como para evitar conflictos de intereses entre la propia entidad, sus financiadores y los intereses de los consumidores; f) hacer pública en términos claros y comprensibles, por cualquier medio adecuado, en particular en su sitio web, información que demuestra que la entidad cumple los criterios mencionados en las letras a) a e), así como información sobre las fuentes de su financiación en general, su estructura organizativa, su gestión y composición, su finalidad estatutaria y sus actividades.

Corresponde al Estado miembro designante velar por que las entidades cumplan los criterios de designación como entidad habilitada para ejercitar acciones de representación transfronterizas, evaluar si la entidad habilitada sigue cumpliéndolos y, en caso necesario, revocar dicha designación (Considerando 29). Los Estados miembros deben evaluar, al menos cada cinco años, si las entidades habilitadas siguen cumpliendo los criterios de designación. Igualmente les corresponde velar por que las entidades habilitadas que hayan sido designadas en otro Estado miembro para ejercitar acciones de representación transfronterizas puedan ejercitar dichas acciones de representación ante sus órganos jurisdiccionales o autoridades administrativas (considerando 31). 
Revista CESCO, N. $36 / 2020$

doi.org/10.18239/RCDC_2020.36.2639
Faustino Cordón Moreno

Examen de los instrumentos de tutela previstos en la Directiva, del

Parlamento y del Consejo, relativa a las acciones de representación para la tutela de los intereses colectivos de los consumidores

particular, deben desempeñar un papel activo a la hora de garantizar que se cumplan las disposiciones pertinentes del Derecho de la Unión. Se debe considerar que todas ellas se encuentran en buena posición para solicitar la condición de entidad habilitada con arreglo al Derecho nacional." Aunque también los organismos públicos "podrían desempeñar un papel activo..., ejercitando acciones de representación tal como se establecen en la presente Directiva."

(ii) Los artículos 5 y 6 de la Directiva precisan el régimen específico de las acciones transfronterizas de representación: por un lado, con el fin de garantizar el reconocimiento mutuo de la legitimación procesal de las entidades habilitadas para el ejercicio de tales acciones los Estados miembros publicarán y comunicarán a la Comisión una lista con las entidades designadas, debiendo esta elaborar una lista de dichas entidades, publicarla y tenerla actualizada (art. 5); esta lista será aceptada por los órganos jurisdiccionales (o autoridades administrativas) como prueba de la legitimación procesal de la entidad habilitada para ejercitar tales acciones, sin perjuicio del derecho del órgano jurisdiccional o autoridad administrativa a examinar si la finalidad estatutaria de la entidad habilitada justifica que ejercite la acción en un caso concreto (art. 6-3). Y por otro, cuando la presunta infracción afecte o pueda afectar a consumidores de distintos Estados miembros, se dispone que la acción de representación pueda ser ejercitada ante el órgano jurisdiccional o autoridad administrativa competente por varias entidades habilitadas en distintos Estados miembros (art. 6.2). Ello, precisa el considerando 31, de conformidad con las correspondientes normas en materia de competencia judicial y sin perjuicio de la prerrogativa del órgano jurisdiccional o autoridad administrativa que conozca del asunto de examinar si la acción de representación es apta para ser tramitada como acción de representación única.

(iii) Los Estados miembros podrán designar a una entidad como entidad habilitada con carácter ad hoc para ejercitar una determinada acción de representación nacional, a petición de dicha entidad, si cumple los criterios de designación como entidad habilitada previstos en el Derecho nacional (art. 4.6), debiendo "existir la posibilidad de que dicha designación la realice el órgano jurisdiccional o autoridad administrativa que conozca del asunto, incluso mediante aceptación, cuando proceda"; aunque "(I)a presente Directiva no debería incentivar" tal posibilidad. En cambio, estas entidades habilitadas designadas con carácter ad hoc no deben poder ejercitar acciones de representación transfronterizas (considerando 28).

\subsection{El estado de la cuestión en el Derecho interno}

(i) Como antes decía, en nuestro ordenamiento están ya previstas estas acciones colectivas para la tutela de los derechos e intereses colectivos de los consumidores, distinguiendo la ley, dentro de ellos, los colectivos en sentido estricto y los difusos, y se reconoce un amplio abanico de legitimación para su ejercicio. Su regulación se encuentra en los arts. 24 LGDCU y 11 LEC y, conforme a ella hay que distinguir: 
Revista CESCO, N. $36 / 2020$

doi.org/10.18239/RCDC_2020.36.2639
Faustino Cordón Moreno

Examen de los instrumentos de tutela previstos en la Directiva, del

Parlamento y del Consejo, relativa a las acciones de representación para la tutela de los intereses colectivos de los consumidores

(a) La tutela de los intereses generales de los consumidores que se encomienda a las asociaciones de consumidores legalmente constituidas como tales asociaciones y, por tanto, con personalidad jurídica (art. 24.1 LGDCU y art. 11.1 LEC).

(b) La tutela de los derechos e intereses colectivos y difusos de los consumidores y usuarios $^{5}$. Cuando se trata de intereses colectivos la legitimación se reconoce a "las asociaciones de consumidores" (legalmente constituidas porque, si no lo están, dispone el art. 24.1, II LGDCU que "sólo podrán representar los intereses de sus asociados o de la asociación, pero no los intereses generales, colectivos o difusos, de los consumidores"), a "las entidades (distintas de las asociaciones de consumidores) legalmente constituidas que tengan por objeto la defensa o protección de estos" y a "los propios grupos de afectados"; en tales casos, "la sentencia estimatoria determinará individualmente los consumidores y usuarios que, conforme a las leyes sobre su protección, han de entenderse beneficiados por la condena". Si se trata de intereses difusos, la legitimación se reconoce exclusivamente a "las asociaciones de consumidores y usuarios que, conforme a la ley, sean representativas" (art. 11.3 LEC), teniendo tal consideración "las que formen parte del Consejo de Consumidores y Usuarios, salvo que el ámbito territorial del conflicto afecte fundamentalmente a una comunidad autónoma, en cuyo caso se estará a su legislación específica" (art. 24.2 LGDCU); en estos supuestos la sentencia "establecerá los datos, características y requisitos necesarios para poder exigir el pago $y$, en su caso, instar la ejecución o intervenir en ella, si la instara la asociación demandante" (v. art. 221.1-1a). Y en ambos casos, si, como presupuesto de la condena o como pronunciamiento principal o único, se declarara ilícita o no conforme a la ley una determinada actividad o conducta, la sentencia determinará si, conforme a la legislación de protección a los consumidores y usuarios, la declaración ha de surtir efectos procesales no limitados a quienes hayan sido partes en el proceso correspondiente.

(c) Este régimen se completa en nuestro derecho con el reconocimiento de legitimación para el ejercicio de la acción de cesación en defensa de los intereses colectivos y de los intereses difusos de los consumidores al Instituto Nacional del Consumo y a los órganos o entidades correspondientes de las comunidades autónomas y de las corporaciones locales competentes en materia de defensa de los consumidores y usuarios (art. 54 LGDCU), y a las entidades habilitadas conforme a la normativa comunitaria (art. 11.4 LEC); y con la atribución de legitimación al Ministerio Fiscal para ejercitar cualesquiera acciones en defensa de los intereses de los consumidores (generales, colectivos o difusos) (art. 11.5 LEC).

(ii) La comparación de esta regulación con la establecida en la Directiva permite establecer estas dos conclusiones: (a) el régimen interno que se acaba de exponer

\footnotetext{
${ }^{5}$ La diferencia entre uno y otro tipo radica no tanto en la naturaleza de los derechos o intereses en cuestión como en el grado de determinación de los consumidores y usuarios interesados: en el primer caso están "perfectamente determinados" o son fácilmente determinables", y en el segundo la pluralidad de consumidores es "indeterminada o de difícil determinación" (art. 11.2 y 3 LEC).
} 
Revista CESCO, N. $36 / 2020$

doi.org/10.18239/RCDC_2020.36.2639
Faustino Cordón Moreno

Examen de los instrumentos de tutela previstos en la Directiva, del Parlamento y del Consejo, relativa a las acciones de representación para la tutela de los intereses colectivos de los consumidores

podrá seguir siendo aplicado cuando se trate del ejercicio de acciones de representación nacionales ${ }^{6}$ porque no se opone al de la Directiva y ésta deja su regulación a la autonomía de los Estados miembros; (b) el Derecho interno deberá incorporar el régimen previsto en la Directiva para cuando las entidades habilitadas ejerciten acciones transfronterizas de representación; en especial las previsiones contenidas en sus artículos $4.3,5$ y 6 , que antes veíamos y no estén previstas. ${ }^{7}$

\section{Los tipos de tutela. Las previsiones de la Directiva y el estado de la cuestión en el Derecho español}

\subsection{En general}

(i) El artículo 7 de la Directiva establece, "al menos", los siguientes tipos de tutela ("medidas") que pueden solicitar las entidades habilitadas cuando se ejercitan este tipo de acciones (de representación o colectivas) por las entidades habilitadas: medidas de cesación y medidas resarcitorias. Junto a ellas el artículo 8 contempla estas otras dos acciones que se dejan a la libre autonomía procesal de los Estados y que el considerando 40 incluye dentro de las de cesación: la acción declarativa de que la práctica constituye la infracción a que se refiere el artículo 2, apartado 1 , y la acción encaminada a obtener la publicación total o parcial de la resolución sobre la medida, o a obtener una declaración de rectificación.

(a) El citado considerando 40 contiene una descripción de las primeras: "Las medidas de cesación deben comprender medidas definitivas y medidas provisionales. Las medidas provisionales podrían consistir en medidas temporales, cautelares y preventivas para poner fin a una práctica en curso o prohibir una práctica en caso de que aún no se haya producido, pero exista el riesgo de que, de producirse, provoque daños o perjuicios graves o irreversibles a los consumidores. Las medidas de cesación también podrían consistir en medidas declarativas de que una práctica concreta constituye una infracción, en los casos en que esa práctica haya cesado antes de que se ejerciten acciones de representación, pero siga siendo necesario declarar que la práctica constituye una infracción, por ejemplo, para facilitar actuaciones de seguimiento de las medidas resarcitorias. Además, las medidas de cesación podrían consistir en la obligación de que el empresario que haya cometido la infracción publique total o parcialmente la resolución al respecto dictada por el órgano jurisdiccional o la autoridad administrativa, en la forma que se considere conveniente, o de que publique una declaración de rectificación."

(b) Con las medidas resarcitorias se persigue restablecer el derecho de los consumidores "a obtener soluciones contractuales y extracontractuales en caso de

\footnotetext{
${ }^{6}$ Aunque quizá con algunas adaptaciones; por ejemplo, introduciendo la previsión de que las entidades habilitadas pueden representar a consumidores de diversos Estados miembros.

7 Porque algunas ya lo están. Por ejemplo, el artículo 11.4 LEC dispone que los Jueces y Tribunales aceptarán la lista de entidades habilitadas comunicada a la Comisión como prueba de su capacidad para ser parte, sin perjuicio de examinar si su finalidad y los intereses afectados legitiman el ejercicio de la acción
} 
Revista CESCO, N. ${ }^{\circ} 36 / 2020$

doi.org/10.18239/RCDC_2020.36.2639
Faustino Cordón Moreno

Examen de los instrumentos de tutela previstos en la Directiva, del Parlamento y del Consejo, relativa a las acciones de representación para la tutela de los intereses colectivos de los consumidores

que sus intereses se hayan visto perjudicados por una infracción, como el derecho a una indemnización por daños y perjuicios, la resolución del contrato, el reembolso, la sustitución, la reparación o la reducción del precio, según corresponda y se disponga de ellas en virtud del Derecho de la Unión o nacional." (considerando 42) ${ }^{8}$.

(ii) Con respecto a estas medidas el citado precepto de la Directiva establece las siguientes disposiciones generales:

(a) Las entidades habilitadas podrán "solicitar las medidas mencionadas... en el marco de una acción de representación única, cuando proceda", pudiendo los Estados miembros disponer que dichas medidas se dicten en una única resolución." Es decir, se prevé una acumulación de acciones facultativa, dejándose en manos de los Estados miembros que puedan regularla como obligatoria.

(b) En el ejercicio de toda acción de representación, la entidad habilitada proporcionará al órgano jurisdiccional o autoridad administrativa información suficiente sobre los consumidores afectados. Esta información -dice el considerando 34- "debe permitir al órgano jurisdiccional o autoridad administrativa determinar si es competente y la ley aplicable. En los casos de responsabilidad civil, dicha obligación implicaría comunicar al órgano jurisdiccional o autoridad administrativa el lugar donde se haya producido o pueda producirse el hecho dañoso que afecte a los consumidores."

(c) Los órganos jurisdiccionales ( 0 , en su caso, autoridades administrativas) examinarán la admisibilidad de la acción de representación ejercitada de conformidad con la Directiva y el Derecho nacional, debiendo procurar los Estados miembros que sus órganos jurisdiccionales (o administrativos) puedan decidir desestimar los

\footnotetext{
${ }^{88}$ En este mismo Considerando se fijan dos límites a estas acciones: (a) Solo podrán ejercitarse "cuando el Derecho de la Unión o nacional prevea dichos derechos sustantivos"; y (b) la Directiva "no debe posibilitar que se impongan indemnizaciones punitivas al empresario que haya cometido la infracción, de conformidad con el Derecho nacional."

${ }^{9}$ El considerando 58, por su parte, pone el énfasis en la información que las entidades deben proporcionar a los consumidores para que una acción de representación resulte eficaz: "En sus sitios web, las entidades habilitadas deben informar a los consumidores acerca de las acciones de representación que hayan decidido ejercitar ante los órganos jurisdiccionales o autoridades administrativas, acerca de la situación de las acciones de representación que hayan ejercitado y de los resultados de dichas acciones, para permitir a los consumidores tomar decisiones informadas sobre si quieren participar a efectos de una acción de representación y permitirles cumplir los trámites correspondientes en el momento oportuno. La información que las entidades habilitadas están obligadas a proporcionar a los consumidores debe incluir, cuando sea pertinente y adecuado, una explicación en lenguaje claro del objeto y de las consecuencias jurídicas posibles o reales de la acción de representación, la intención de la entidad habilitada de ejercitar la acción de representación, una descripción del grupo de consumidores afectados por la acción de representación, así como los trámites necesarios que deben cumplir los consumidores afectados, incluido el aseguramiento de las pruebas necesarias, a fin de que los consumidores puedan beneficiarse de las medidas de cesación, de las medidas resarcitorias o de los acuerdos homologados tal como se establece en la presente Directiva. Dicha información debe ser adecuada y proporcionada a las circunstancias del caso."
} 
Revista CESCO, N. $36 / 2020$

doi.org/10.18239/RCDC_2020.36.2639
Faustino Cordón Moreno

Examen de los instrumentos de tutela previstos en la Directiva, del

Parlamento y del Consejo, relativa a las acciones de representación para la tutela de los intereses colectivos de los consumidores

asuntos manifiestamente infundados en la fase más temprana posible del procedimiento de conformidad con el Derecho nacional.

Además, precisa el Considerando 48 que los Estados miembros "deben establecer normas para la coordinación entre acciones de representación, acciones individuales ejercitadas por los consumidores y cualquier otra acción destinada a proteger los intereses individuales y colectivos de los consumidores."

(iii) Pues bien, todas las acciones mencionadas están previstas en nuestro ordenamiento: Por un lado, el artículo 53 LGDCU (también los arts. 11 y 221.4 LEC) reconoce la legitimación de las asociaciones de consumidores (y a las entidades previstas en el art. 54 LGDCU) para ejercitar las acciones de cesación y resarcitorias a que se refiere la Directiva; incluso contempla acciones que ésta no menciona, como, por ejemplo, las de nulidad o anulabilidad. Por otro, pueden solicitar "ante litem", con la demanda o dentro del proceso iniciado, que será el ordinario que corresponda con las especialidades que prevé la LEC, medidas cautelares, incluida la prevista en el art. 727-7a: "La orden judicial de cesar provisionalmente en una actividad; la de abstenerse temporalmente de llevar a cabo una conducta; o la prohibición temporal de interrumpir o de cesar en la realización de una prestación que viniera llevándose a cabo".

Igualmente está prevista la primera de las normas generales antes vistas, relativa a la acumulación, que el art. 53, IV LGDCU regula con carácter facultativo, aunque no existiría obstáculo a que el legislador la considerara obligatoria (art. 73.2 LEC). En cambio, al realizar la transposición de la Directiva al Derecho interno deberán tenerse en cuenta las normas antes vistas sobre la información que deben proporcionar las entidades habilitadas y sobre la previsión de un trámite inicial (en fase de admisión de la demanda o, a lo más tardar, en la audiencia previa o en la vista del juicio verbal) para la inadmisión o desestimación de las acciones manifiestamente infundadas; siquiera esta segunda previsión deba tener en cuenta la norma general sobre admisión de la demanda del art. 403 LEC y el derecho de acceso a la jurisdicción que forma parte del contenido esencial del derecho a la tutela judicial efectiva del artículo 24.1 CE.

\subsection{Medidas de cesación}

(i) Con respecto a estas medidas, que tienen carácter preceptivo, el artículo $8^{\circ}$ de la Directiva establece las siguientes normas específicas:

(a) Para que la entidad habilitada pueda solicitarlas, el consumidor no estará obligado a manifestar su voluntad de estar representado por ella.

(b) Dicha entidad no tendrá la obligación de demostrar ni la pérdida, daño o perjuicio efectivo de los consumidores considerados individualmente que se vean afectados 
Revista CESCO, N. $36 / 2020$

doi.org/10.18239/RCDC_2020.36.2639
Faustino Cordón Moreno

Examen de los instrumentos de tutela previstos en la Directiva, del Parlamento y del Consejo, relativa a las acciones de representación para la tutela de los intereses colectivos de los consumidores

por la infracción ${ }^{10}$ ni el dolo o negligencia del empresario, porque "(u)na decisión sobre una medida de cesación no debe depender de que la práctica se realizase con dolo o por negligencia" (considerando 33).

(c) Los Estados miembros podrán introducir disposiciones en su Derecho interno, o mantener las que ya existan, por las que el ejercicio de la acción por la entidad se supedite a la previa consulta al empresario de que se trate, para que (en el plazo de dos semanas) este cese la infracción a que se refiere el artículo 2, apartado 1; debiendo notificar a la Comisión las disposiciones de ese tipo que existan en el Derecho nacional y garantizando la Comisión que dicha información estará a disposición del público.

(ii) La adaptación de esta normativa al Derecho interno español exigirá tener en cuenta la conveniencia de introducir en las acciones de cesación esta reclamación previa (la Directiva no la impone), que el legislador español ya ha previsto en los artículos 3 y 4 del RDLey 1/2017, de 20 de enero, de medidas urgentes de protección de consumidores en materia de cláusulas suelo.

\subsection{Medidas resarcitorias}

(i) En el artículo 9 de la Directiva se regulan las acciones colectivas reparadoras o resarcitorias ejercitadas por las entidades encaminadas a obtener del empresario "soluciones, como la indemnización, la reparación, la sustitución, la reducción del precio, la resolución del contrato o el reembolso del precio pagado, según corresponda y se disponga de ellas en virtud del Derecho de la Unión o nacional." Las normas específicas que se prevén son las siguientes:

(a) Debe obligarse a las entidades habilitadas a proporcionar información suficiente para fundar estas acciones, incluida una descripción del grupo de consumidores afectados por la infracción y las cuestiones de hecho y de Derecho que deben resolverse en el marco de la acción de representación (Considerando 49).

(b) No puede obligarse a estas entidades a identificar individualmente a todos los consumidores afectados, pero sí, al menos, a describir el grupo de consumidores que tienen derecho a las soluciones que esas medidas resarcitorias proporcionan y, en su caso, a indicar el método de cuantificación del daño o perjuicio y los trámites correspondientes que deban cumplir los consumidores y los empresarios para que se apliquen las soluciones, porque "(I)os consumidores que tengan derecho a esas

\footnotetext{
10 Como dice el considerando 33, "tienen por objeto la protección de los intereses colectivos de los consumidores independientemente de cualquier pérdida, daño o perjuicio efectivo que pueda haber sufrido un consumidor concreto"; y precisa el considerando 37: "En las acciones de representación para obtener medidas de cesación, el beneficio para los consumidores afectados sería la cesación o prohibición de la práctica que constituya una infracción."
} 
Revista CESCO, N. $36 / 2020$

doi.org/10.18239/RCDC_2020.36.2639
Faustino Cordón Moreno

Examen de los instrumentos de tutela previstos en la Directiva, del Parlamento y del Consejo, relativa a las acciones de representación para la tutela de los intereses colectivos de los consumidores

soluciones deben poder beneficiarse de ellas sin tener que iniciar un procedimiento distinto" (Considerando 50).

(c) El órgano jurisdiccional o autoridad administrativa debe comprobar en la fase más temprana posible del procedimiento si el asunto es apto para serle sometido mediante una acción de representación, teniendo en cuenta la naturaleza de la infracción y las características de los daños o perjuicios sufridos por los consumidores afectados (Considerando 50).

(d) Dentro del proceso en que se ejercite la acción de representación el Derecho interno deberá prever "la manera y la fase (siempre dentro de un plazo adecuado después de haberse ejercitado la acción)... en que los consumidores individuales afectados por la acción de representación manifiesten expresa o tácitamente su voluntad... de ser representados o no por la entidad habilitada en dicha acción de representación y de quedar vinculados o no por el resultado de la acción."11

(e) Se establecerán normas para garantizar que los consumidores que hayan manifestado, expresa o tácitamente, su voluntad de ser representados en una acción de representación no puedan ser representados en otras acciones, ni ejercitar acciones individualmente, con el mismo objeto y causa contra el mismo empresario. Del mismo modo, se establecerán normas para garantizar que los consumidores no sean indemnizados más de una vez por el mismo objeto y causa.

(f) Cuando una medida resarcitoria no especifique de manera individual a los consumidores que pueden beneficiarse de las soluciones que proporcione, delimitará al menos el grupo de consumidores que pueden ser beneficiados: "Por motivos de diligencia y eficiencia, los Estados miembros, con arreglo al Derecho nacional, han de poder ofrecer a los consumidores la posibilidad de beneficiarse directamente de una medida resarcitoria después de que haya sido dictada, sin que se le exijan requisitos relativos a su participación previa en la acción de representación" (Considerando 47).

(g) Los Estados miembros deberán tener en cuenta que las medidas resarcitorias sean eficaces por sí mismas sin necesidad de ejercitar otra acción; y que, por lo tanto, las entidades habilitadas pueden ejercitar estas acciones de representación sin necesidad de que un órgano jurisdiccional o autoridad administrativa haya declarado previamente la existencia de la infracción en un procedimiento distinto.

\footnotetext{
${ }^{11}$ Dice al respecto el Considerando 43 que "los Estados miembros deben prever un mecanismo de inclusión voluntaria o de exclusión voluntaria, o una combinación de ambos. En un mecanismo de inclusión voluntaria, los consumidores deben estar obligados a manifestar expresamente su voluntad de ser representados por la entidad habilitada para ejercitar la acción de representación para obtener medidas resarcitorias. En un mecanismo de exclusión voluntaria, los consumidores deben estar obligados a manifestar expresamente su voluntad de no ser representados por la entidad habilitada para ejercitar la acción de representación para obtener medidas resarcitorias."
} 
Revista CESCO, N. $36 / 2020$

doi.org/10.18239/RCDC_2020.36.2639
Faustino Cordón Moreno

Examen de los instrumentos de tutela previstos en la Directiva, del

Parlamento y del Consejo, relativa a las acciones de representación para la tutela de los intereses colectivos de los consumidores

(h) El Derecho interno deberá regular los plazos dentro de los cuales los consumidores individualmente considerados pueden beneficiarse de medidas resarcitorias.

(i) Las soluciones que las medidas resarcitorias proporcionen en el marco de una acción de representación se entenderán sin perjuicio de cualquier solución adicional de que dispongan los consumidores en virtud del Derecho de la Unión o nacional que no haya sido objeto de dicha acción de representación.

(j) Conforme al art. 12.2 de la Directiva, "(I)os consumidores individuales afectados por una acción de representación para obtener medidas resarcitorias no soportarán las costas procesales", con excepción de los casos en que hayan sido causadas por la conducta dolosa o negligente del consumidor de que se trate (art. 12.3). A los demás sujetos intervinientes se aplicará el criterio del vencimiento "con las condiciones y excepciones previstas en el Derecho nacional aplicable al proceso judicial en general" (art. 12.1).

(k) Cuando el Derecho interno permita que estas acciones sean financiadas por un tercero, deberán adoptarse medidas para evitar los conflictos de intereses y que la financiación por parte del tercero que tenga un interés económico en el ejercicio o el resultado de dicha acción no aparte la acción de representación de la protección de los intereses colectivos de los consumidores (art. 10.1), A estos efectos, los Estados miembros deberán procurar: que, por ejemplo, la acción de representación no se ejercite contra un demandado que sea un competidor del financiador o contra un demandado del que dependa el financiador (art. 10.2); que los órganos jurisdiccionales (o, en su caso, autoridades administrativas) estén facultados para valorar el cumplimiento de las medidas adoptadas, en caso de que surjan dudas fundadas acerca de tal cumplimiento; que, para ello, las entidades habilitadas deban comunicar al órgano jurisdiccional o autoridad administrativa un resumen financiero de las fuentes de financiación utilizadas para apoyar la acción de representación; que los órganos jurisdiccionales (o autoridades administrativas, en su caso) estén facultados para adoptar las medidas adecuadas, como, por ejemplo, exigir a la entidad habilitada que rechace o modifique la financiación controvertida y, de ser necesario, denegar legitimación procesal a la entidad habilitada en una determinada acción de representación, aunque dicha denegación no podrá perjudicar los derechos de los consumidores afectados por esa acción de representación.

(ii) La transposición de la Directiva a nuestro Derecho interno en los que a estas acciones resarcitorias colectivas se refiere requerirá tener presente:

(a) Algunas de sus normas ya están contempladas en nuestro ordenamiento. Así, las que regulan la intervención de los consumidores individuales en los procesos instados por las asociaciones (art. 15, apartados 1 a 3, de la LEC, aunque el alcance de esta norma deberá precisarse a la luz de la declaración de la Directiva -a la que luego me refiero- de que esos consumidores individuales no pueden ser parte demandante en 
Revista CESCO, N. $36 / 2020$

doi.org/10.18239/RCDC_2020.36.2639
Faustino Cordón Moreno

Examen de los instrumentos de tutela previstos en la Directiva, del

Parlamento y del Consejo, relativa a las acciones de representación para la tutela de los intereses colectivos de los consumidores

el procedimiento); el contenido y la eficacia frente a ellos de la sentencia que se dicte (art. 221 LEC) o el reconocimiento a los mismos de la acción ejecutiva fundada en sentencia de condena sin determinación individual de los beneficiados, previo su reconocimiento como tales (art. 519 LEC).

(b) El régimen de la condena en costas en estos procesos, previsto en el artículo 12.2 de la Directiva, ha sido incorporado ya por la jurisprudencia del Tribunal Supremo (cfr., por ejemplo, la STS 510/2020, de 6 de octubre, y sentencias que cita).

(c) Deberá prestarse especial atención a la exigencia de la Directiva (art. 10) de total transparencia de las entidades habilitadas "frente a los órganos jurisdiccionales o autoridades administrativas respecto de la fuente de financiación de sus actividades en general y respecto de los fondos que apoyen una acción de representación específica para obtener medidas resarcitorias" (Considerando 52).

\subsection{Acuerdos de resarcimiento}

(i) El artículo 11 de la Directiva regula estos acuerdos que pueden alcanzar la entidad habilitada y el empresario presunto autor de la infracción, en el marco de una acción de representación para obtener medidas resarcitorias, bien de mutuo acuerdo bien, previa consulta de las partes, a propuesta del órgano judicial (o, en su caso, de la autoridad administrativa). La Directiva dice que estos acuerdos "deben fomentarse" (Considerando 53) y remite a los Estados miembros la regulación del procedimiento, previendo las siguientes medidas:

(a) Los acuerdos estarán sujetos a homologación por el órgano jurisdiccional o autoridad administrativa, que podrán denegarla si el acuerdo en cuestión es contrario a normas imperativas de Derecho nacional o incluye condiciones que no puedan cumplirse, teniendo en cuenta los derechos e intereses de todas las partes, y en particular los de los consumidores afectados. La Directiva, además, faculta a los Estados miembros para establecer normas que permitan al órgano jurisdiccional o autoridad administrativa denegar la homologación de un acuerdo por no ser equitativo.

(b) Los acuerdos homologados serán vinculantes para la entidad habilitada, el empresario y los consumidores individuales afectados; pero el Derecho interno podrá establecer normas que permitan a los consumidores individuales afectados aceptarlos o rechazar quedar vinculados por ellos.

(c) El resarcimiento obtenido a través de un acuerdo homologado se entenderá sin perjuicio de cualquier solución adicional de que dispongan los consumidores en virtud del Derecho de la Unión o nacional que no haya sido objeto de dicho acuerdo.

(ii) La posibilidad de alcanzar estos acuerdos está prevista con carácter general en el artículo 414.1 en sede de la audiencia previa del juicio ordinario, y por el artículo 
Revista CESCO, N. $36 / 2020$

doi.org/10.18239/RCDC_2020.36.2639
Faustino Cordón Moreno

Examen de los instrumentos de tutela previstos en la Directiva, del Parlamento y del Consejo, relativa a las acciones de representación para la tutela de los intereses colectivos de los consumidores

443.1 en la vista del juicio verbal. La transposición de la Directiva solo exigirá decidir sobre la conveniencia (la Directiva lo deja a la autonomía de los Estados) de regular la posible desvinculación de los consumidores individuales afectados del acuerdo de que se trate. Habrá que tener en cuenta también las previsiones contenidas en el Anteproyecto de Ley de Medidas de Eficiencia procesal del Servicio público de Justicia, recientemente publicado.

\section{Medidas procesales}

(i) Corresponde a los Estados miembros la decisión de reconocer a los consumidores individuales afectados determinados derechos en el marco de la acción de representación, "pero esos consumidores individuales no pueden ser parte demandante en el procedimiento. Los consumidores individuales no deben poder interferir en ningún caso en las decisiones relativas al procedimiento que tomen las entidades habilitadas, solicitar individualmente pruebas en el marco del procedimiento ni recurrir individualmente las decisiones de procedimiento del órgano jurisdiccional o autoridad administrativa ante el que se ejercite la acción de representación. Tampoco deben tener obligaciones procesales en el marco de la acción de representación ni soportar las costas procesales, excepto en circunstancias excepcionales" (considerando 36).

(ii) Dispone el artículo 15 que los Estados miembros velarán por que las resoluciones firmes de los órganos jurisdiccionales o autoridades administrativas de cualquier Estado miembro, que declaren la existencia de una infracción que perjudique los intereses colectivos de los consumidores, puedan ser alegadas por todas las partes como prueba en el contexto de cualquier otra acción ante sus órganos jurisdiccionales o autoridades administrativas nacionales, para solicitar medidas resarcitorias contra el mismo empresario por la misma práctica, de conformidad con la normativa nacional sobre valoración de la prueba.

(iii) El artículo 20 prevé la asistencia de los Estados miembros a las entidades habilitadas con medidas destinadas a garantizar que las costas procesales relacionadas con las acciones de representación no impidan a las entidades habilitadas ejercitar las acciones que les competen.

(iv) Se prevé que el ejercicio de las acciones de cesación y resarcitorias por las entidades habilitadas interrumpa la prescripción de las acciones que puedan corresponder a los consumidores afectados (art. 16).

(v) La previsión de que las acciones de representación para obtener las medidas de cesación se tramitarán mediante un procedimiento acelerado (art. 24.2) ya se cumple en nuestro ordenamiento, que prevé para ellas el cauce del juicio verbal (art. 250.112 LEC). 
Revista CESCO, N.․ 36/2020

doi.org/10.18239/RCDC_2020.36.2639
Faustino Cordón Moreno

Examen de los instrumentos de tutela previstos en la Directiva, del

Parlamento y del Consejo, relativa a las acciones de representación para la tutela de los intereses colectivos de los consumidores

(vi) Especial relevancia tiene la norma del artículo 18, que faculta al órgano judicial (o administrativo) para ordenar que el demandado o tercero exhiba las pruebas que obren en su poder, "de conformidad con las normas procesales nacionales" y "sin perjuicio de las normas de la Unión y nacionales aplicables en materia de confidencialidad y proporcionalidad." La cuestión que se plantea es si, al transponer la Directiva al Derecho interno, se optará por las normas previstas en los artículos 283 bis-a) y siguientes de la LEC, que regulan la exhibición de las pruebas en procesos para el ejercicio de acciones por daños derivados de infracciones del Derecho de la competencia, o se optará por mantener el régimen general de exhibición de documentos en poder de la contraparte o de terceros de los artículos 328 y siguientes. 